\title{
Radiomics signature for prediction of N2 disease: fascinating but still a long way to go for clinical application
}

\author{
Kwon Joong $\mathrm{Na}^{1}$, Hongyoon $\mathrm{Choi}^{2}$, Young Tae $\mathrm{Kim}^{1,3 \wedge}$ \\ ${ }^{1}$ Department of Thoracic and Cardiovascular Surgery, Seoul National University Hospital, Seoul, Republic of Korea; ${ }^{2}$ Department of Nuclear \\ Medicine, Seoul National University Hospital, Seoul, Republic of Korea; ${ }^{3}$ Cancer Research Institute, Seoul National University College of Medicine, \\ Seoul, Republic of Korea \\ Correspondence to: Young Tae Kim, MD, PhD. Department of Thoracic and Cardiovascular Surgery, Seoul National University Hospital, 101 Daehak- \\ ro, Jongno-gu, Seoul 03080, Republic of Korea. Email: ytkim@snu.ac.kr. \\ Comment on: Yang M, She Y, Deng J, et al. CT-based radiomics signature for the stratification of N2 disease risk in clinical stage I lung \\ adenocarcinoma. Transl Lung Cancer Res 2019;8:876-85.
}

Submitted Apr 30, 2020. Accepted for publication May 26, 2020.

doi: $10.21037 /$ tlcr-20-620

View this article at: http://dx.doi.org/10.21037/tlcr-20-620

Predicting malignant involvement of mediastinal lymph nodes is crucial in determining the best curative treatment strategy. Considering that approximately $10 \%$ of patients with clinical stage I lung cancer are eventually identified to have positive lymph node metastasis by surgical lymph node staging, through evaluation of mediastinal staging is required $(1,2)$. Currently, clinical staging of lung cancer is usually based on noninvasive imaging modalities, and the likelihood of tumor involvement of mediastinal lymph nodes relies on visual criteria. Computed tomography (CT) is the most commonly used modality for the evaluation of patients with lung cancer. However, the median sensitivity and specificity of CT scan for diagnosing mediastinal lymph node metastasis were only $55 \%$ and $81 \%$, respectively (3). Positron emission tomography provides a more accurate evaluation of mediastinal lymph node staging with an overall sensitivity of $73 \%$ and specificity of $92 \%$ (4). Because of the possibility of false-negative in noninvasive imaging, several guidelines recommend invasive mediastinal staging using either endobronchial ultrasound-guided transbronchial needle aspiration or mediastinoscopic biopsy $(3,5)$. Given the reported incidence of mediastinal lymph node metastasis is around $5-10 \%$ in clinical stage I lung cancer patients, the selective use of invasive mediastinal staging has been suggested $(1,2)$. However, there is no consensus on the indication of invasive mediastinal staging; thus, we rely on multiple factors, including clinical staging, tumor location, and clinical characteristics, to performing invasive procedures.

Radiomics is an emerging field of research that focuses on extracting a large number of quantitative features from medical images, and it can provide a more detailed quantification of characteristics for lung nodules. Several studies have generated considerable excitement in oncology regarding the potential of radiomics features as an adjunct to oncologic decision making: differentiation between benign and malignant nodules, prediction of metastatic disease, identification of favorable subsets among malignancies, and prediction of response to chemo/ radiotherapy. In a recent study published in Transl Lung Cancer Res, Yang et al. (6) developed a risk stratification model for predicting N2 metastasis in clinical stage 1 lung adenocarcinoma based on CT-based radiomics signature. They extracted radiomics features using 'PyRadiomics', one of the cutting-edge algorithms, from a substantial number of patients. Their radiomics signature showed better predictive performance than clinical factors for N2 disease prediction in the training set, as well as the validation set. Their data highlights the future incorporation of radiomics into clinical practice for predicting occult $\mathrm{N} 2$ disease in lung adenocarcinoma patients. The accurate prediction of $\mathrm{N} 2$ disease using noninvasive imaging is valuable as it can

\footnotetext{
^ ORCID: 0000-0001-9006-4881.
} 
select high-risk patients who may need invasive mediastinal staging. However, rigorous validation is required for the real application in the clinical setting, and their study design needs external validation. Most machine learning techniques, including LASSO, usually use three different data sets: training set, validation set, and test set. The role of the validation set is to prevent the model from overfitting to the training data and to pick up a model that generally fits best for all data sets. Then, the chosen model should be evaluated in the test set. However, it seems that they selected the model with the maximum AUC within the training set, and it brings concern about the overfitting issue of their model.

Although the rosy outlook for precision medicine through radiomics within the clinical routine has been continued for a decade, nothing is still involved in standardof-care. One of the critical issues is standardization for a generalized model. As image acquisition, reconstruction algorithms, and segmentation methods affect radiomic features, standardized and external validation for multiple centers with different imaging settings is needed (7). Another issue is that it is difficult to explain the plausible explanation for the prediction. For example, a feature 'graylevel variance' is difficult to grasp what characteristics it has in visual interpretation. Even if the accuracy is lowered than the radiomics approach, intuitive quantitative variables such as size, a fraction of solid portion, and FDG uptake are clinically acceptable because of this interpretability. In addition, rigorous comparative studies with these wellknown quantitative variables will be needed in the future. Nonetheless, accurate prediction of N2 disease based on radiomics with future rigorous validation will provide precise risk stratification, which leads to personalized management plans, including selective invasive mediastinal staging.

\section{Acknowledgments}

Funding: None.

\section{Footnote}

Provenance and Peer Review: This article was commissioned by the editorial office, Translational Lung Cancer Research. The article did not undergo external peer review.
Conflicts of Interest: All authors have completed the ICMJE uniform disclosure form (available at http://dx.doi. org/10.21037/tlcr-20-620). The authors have no conflicts of interest to declare.

Ethical Statement: The authors are accountable for all aspects of the work in ensuring that questions related to the accuracy or integrity of any part of the work are appropriately investigated and resolved.

Open Access Statement: This is an Open Access article distributed in accordance with the Creative Commons Attribution-NonCommercial-NoDerivs 4.0 International License (CC BY-NC-ND 4.0), which permits the noncommercial replication and distribution of the article with the strict proviso that no changes or edits are made and the original work is properly cited (including links to both the formal publication through the relevant DOI and the license). See: https://creativecommons.org/licenses/by-nc-nd/4.0/.

\section{References}

1. Lee PC, Port JL, Korst RJ, et al. Risk factors for occult mediastinal metastases in clinical stage I non-small cell lung cancer. Ann Thorac Surg 2007;84:177-81.

2. Haruki T, Aokage K, Miyoshi T, et al. Mediastinal nodal involvement in patients with clinical stage I non-small-cell lung cancer: possibility of rational lymph node dissection. J Thorac Oncol 2015;10:930-6.

3. Silvestri GA, Gonzalez AV, Jantz MA, et al. Methods for staging non-small cell lung cancer: diagnosis and management of lung cancer: American College of Chest Physicians evidence-based clinical practice guidelines. Chest 2013;143:e211S-e250S.

4. Lv YL, Yuan DM, Wang K, et al. Diagnostic performance of integrated positron emission tomography/computed tomography for mediastinal lymph node staging in nonsmall cell lung cancer: a bivariate systematic review and meta-analysis. J Thorac Oncol 2011;6:1350-8.

5. De Leyn P, Dooms C, Kuzdzal J, et al. Revised ESTS guidelines for preoperative mediastinal lymph node staging for non-small-cell lung cancer. Eur J Cardiothorac Surg 2014;45:787-98.

6. Yang $M$, She Y, Deng J, et al. CT-based radiomics signature for the stratification of $\mathrm{N} 2$ disease risk in clinical 
stage I lung adenocarcinoma. Transl Lung Cancer Res 2019;8:876.

7. Traverso A, Wee L, Dekker A, et al. Repeatability and reproducibility of radiomic features: a systematic review. Int J Radiat Oncol Biol Phys 2018;102:1143-58.

Cite this article as: $\mathrm{Na}$ KJ, Choi H, Kim YT. Radiomics signature for prediction of $\mathrm{N} 2$ disease: fascinating but still a long way to go for clinical application. Transl Lung Cancer Res 2020;9(6):2308-2310. doi: 10.21037/tlcr-20-620 